\title{
Blastocrithidia frustrata sp. n. (Kinetoplastea, Trypanosomatidae) from the brown marmorated stink bug Halyomorpha halys (Stål) (Hemiptera, Pentatomidae)
}

\section{Marina Malysheva, Anna Ganyukova and Alexander Frolov}

Zoological Institute, Russian Academy of Sciences, 199034 St. Petersburg, Russia

| Submitted July 8, 2020 | Accepted August 10, 2020|

\begin{abstract}
Summary
The article describes a new species of monoxenous trypanosomatids Blastocrithidia frustrata from brown marmorated stink bugs Halyomorpha halys collected in the south of Russia (Sochi) and Abkhazia (Sukhumi). A unique morphological feature distinguishing this new species from the earlier described representatives of the genus Blastocrithidia is a developed zone of flagellum attachment to rostrum (FAZ), which is represented by macular hemidesmosomes. The presence of FAZ used to be considered a characteristic feature of dixenous flagellates of Trypanosoma genus. Phylogenetic analyses based on sequences of $18 \mathrm{~S}$ rRNA gene has demonstrated that B. frustrata is included into the monophyletic cluster within the limits of the clade comprised of Blastocrithidia spp. This cluster includes, among others, the isolates, which were earlier identified among the Hemiptera in China (Typing Units Ch7) and Papua New Guinea (TU63). Isolates $332 \mathrm{MK}$ and 4 femMK, which we address in our research, prove to be $100 \%$ identical to the isolates from Ch7 and TU63 in terms of sequences of $18 \mathrm{~S}$ rRNA. However, our experimental deciphering of the life cycle of $B$. frustrata in $H$. halys revealed an unstable pattern of infections. Although the development of these trypanosomatids in the host after experimental infection occurs according to the scenario typical for Blastocrithidia and results in the formation of cyst-like amastigotes (=straphangers), the vertical transmission of parasites (from parent to offspring) does not take place, while horizontal one occurs rarely, if ever. This allows to conclude that $H$. halys is a nonspecific host for $B$. frustrata.
\end{abstract}

Key words: Blastocrithidia, brown marmorated stink bug, host-parasite relationship, life cycle, phylogeny, Trypanosomatidae, ultrastructure

\section{Introduction}

The family Trypanosomatidae is traditionally divided into two groups of a non-taxonomic rank, i.e. monoxenous and dixenous trypanosomatids
(Maslov et al., 2019). Dixenous trypanosomatids, which have two hosts during their life cycle, use vertebrates (genera Trypanosoma and Leishmania) or plants (genus Phytomonas) as reservoir hosts, while their vectors are in most cases insects and,

doi:10.21685/1680-0826-2020-14-3-3 
less often, leeches (only for some Trypanosoma). Dixenous trypanosomatids can cause dangerous diseases in humans and domestic animals, as well as in a number of plants (Hoare, 1972; Parthasarathy et al., 1976; Kitajima, 1986; Camargo, 1999; Jaskowska et al., 2015; Akhoundi et al., 2016). Due to objective reasons, dixenous trypanosomatids have been provoking the greatest interest among researchers. However, monoxenous trypanosomatids, whose life cycle normally proceeds in a single host (insect), appear to be a no less attractive group of trypanosomatids, both in terms of theory and practice (Maslov et al., 2013; Lukeš et al., 2018).

Monoxenous trypanosomatids are a considerably more diverse and numerous group, currently amounting to 18 genera. At present, the majority of researchers accept the independent origin of all the three genera of dixenous trypanosomatids from different and unrelated monoxenous ancestors (Maslov et al., 2013; Frolov et al., 2015; Lukeš et al., 2018). For this reason, a natural assumption would be that dealing with many important issues related, in particular, to the origin and genesis of dixeny in trypanosomatids is not possible without an understanding of major evolutionary trends actualized in different phylogenetic lines of monoxenous flagellates. Much evidence has been collected to demonstrate that some of these "harmless" trypanosomatids can act as agents of opportunistic infections of humans and animals (Dedet et al., 1995; Pacheco et al., 1998; Dedet and Pratlong, 2000; Garin et al., 2001; Chicharro and Alvar, 2003; Ghosh et al., 2012), and negatively affect their immediate insect hosts, causing their death or fertility decline (Schaub and Schnitker, 1988; Schaub and Jensen, 1990; Yourth and SchmidHempel, 2006; Hamilton et al., 2015; Ravoet et al., 2015). The last point allows considering some monoxenous trypanosomatids as potential objects for biological control.

Brown marmorated stink bug Halyomorpha halys (Hemiptera, Pentatomidae), native to China, Japan, Korea and other countries of Southeast Asia, has recently acquired a reputation of the most deleterious invasive insect in North America and Europe (Haye et al., 2015). The earliest mention of $H$. halys detected in the USA dates back to 1996 (Hoebeke and Carter, 2003). By now it has spread almost all around the USA (found in more than 40 states), the southern provinces of Canada, in the majority of European countries and in the Krasnodar Territory (Krasnodarskiy Kray) in the south of Russia (Arnold, 2009; Fogain and Graff, 2011; Heckmann, 2012; Callot and Brua, 2013; Cesari et al., 2014; Gariepy et al., 2014; Milonas and Partsinevelos, 2014; Vetek et al., 2014; Haye et al., 2015; Gapon, 2016; Mityushev, 2016). Having no natural enemies in the areas it occupies, the brown marmorated stink bug inflicts substantial damage on many fruit and decorative crops, sometimes destroying harvests completely.

Along with the description of a new species of monoxenous trypanosomatids Blastocrithidia frustrata from brown marmorated stink bugs, the present study also aims to assess whether these parasitic protists would be able to control the population size of $H$. halys.

\section{Material and methods}

\section{Collection AND CUltivation OF INSECTS}

Brown marmorated stink bugs Halyomorpha halys have been collected in Privokzal'ny District

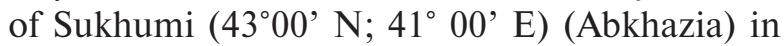
autumn of 2018 and in Khostinsky District of Sochi

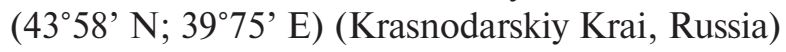
in the falls of 2018 and 2019. Along with natural materials, we also examined stink bugs from two laboratory lines (Sochian and Abkhazian), which had been cultivated in the laboratory for three years prior to this study.

The collection of insects did not require specific permissions, since they were sampled in places of public access, and $H$. halys is not an endangered or protected species.

The stink bugs were kept in round plastic containers, $12 \mathrm{~cm}$ in diameter and $12 \mathrm{~cm}$ high, or in rectangular plastic containers (length $20 \mathrm{~cm}$; width $11 \mathrm{~cm}$; height $12 \mathrm{~cm}$ ) with holes for air circulation. The temperature of $26^{\circ} \mathrm{C}$ and $16 \mathrm{~h}$ light: $8 \mathrm{~h}$ dark photoperiod were maintained in the insectary. The stink bugs were fed with carrot (Daucus carota), peanut seeds (Arachis hypogaea) and sprouted beans (Vicia faba). Troughs with drinking water were kept in the containers all the time.

\section{DisSECTION OF INSECTS}

Before the dissection, the insects were immobilized with chloroform vapors, then we severed a limb, microscoped a drop of discharged hemolymph and dissected the insect in $0.9 \%$ saline solution. 


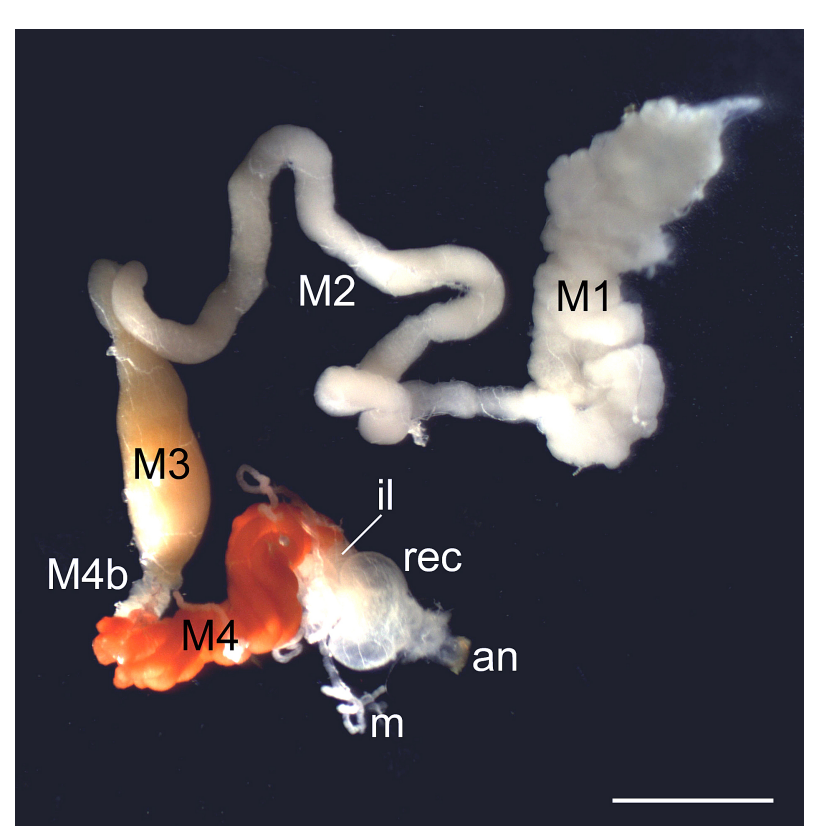

Fig. 1. Isolated digestive tract of Halyomorpha halys. Abbreviations: M1-M4, M4b - segments of the midgut; an - anus; il - ileum; $\mathrm{m}$ - Malpighian tubules; rec - rectum. Scale bar: $1 \mathrm{~mm}$.

Salivary glands and intestine were examined with Leica DM2500 microscope (Leica Microsystems, Wetzlar, Germany). All the segments of the digestive system (M1-M4, M4b, ileum and rectum) were studied separately (Fig. 1). In the cases of detection of trypanosomatids, we used part of the intestine segment for dry smears, and the other fragments - for DNA extraction, electron microscopy and establishing the cultures.

\section{Cultivation OF TRYPAnOSOMATIDS}

Intestine fragments of the infected stink bugs $H$. halys were placed into $2 \mathrm{ml}$ test tubes filled to the brim with TC-100 (Sigma-Aldrich, St. Louis, USA) supplemented with 10\% Fetal Bovine Serum (BioloT, St. Petersburg, Russia), $500 \mu \mathrm{g} / \mathrm{ml}$ of streptomycin and 500 units/ml of penicillin (SigmaAldrich, St. Louis, USA). Later, after sustainable development of flagellates had been achieved, the cultures were maintained without antibiotic solution at a temperature of $22^{\circ} \mathrm{C}$, being passaged every 14 days.

\section{LIGHT MICROSCOPY}

The smears prepared from the cultures and from fragments of infected intestine were air-dried, fixed with $96 \%$ ethanol for $30 \mathrm{~min}$, and Giemsa-stained for $30 \mathrm{~min}$ ( $\mathrm{pH}$ 6.8). To visualize DNA-containing structures, cells were stained with 4',6-diamidino-2phenylindole (DAPI) $(1 \mathrm{mg} / \mathrm{ml})$ as described earlier (Yurchenko et al., 2006).

Microphotographs were taken using Leica DM 2500 microscope equipped with UCMOS14000KPA 14-Mpx camera (Toup Tek, Hangzhou, China) at $\times 1,000$ magnification. All cell measurements $(n=32)$ and the statistical analysis were performed in UTHSCSA Image Tool for Windows v.3.0.

\section{TRANSMISSION AND SCANNING ELECTRON MICROSCOPY}

Fragments of different intestine segments and the previously centrifuged culture of Blastocrithidia frustata were prepared for TEM, as described earlier (Frolov et al., 2016). Ultrathin sections were examined in Morgagni 268-D microscope (FEI Company/Thermo Fisher Scientific, Hillsboro, OR, USA) with accelerating voltage of $80.00 \mathrm{kV}$.

For the scanning electron microscopy, the culture was centrifuged and prepared for examination according to the method described by Ganyukova with co-authors (Ganyukova et al., 2019). Then it was microscoped in Tescan Mira3 LMU with accelerating voltage of $25.00 \mathrm{kV}$.

DNA ISOLATION, AMPLIFICATION, AND SEQUENCING

Genomic DNA from flagellate cultures and host intestines was extracted using PureLink Genomic DNA Kit (Invitrogen) for DNA extraction. 18S gene fragment was amplified using specific primers S762 and S763, as described previously (Maslov et al., 1996; Kostygov and Frolov, 2007). The resulting PCR fragments were extracted from the reaction mixture, purified with Cleanup Standard Kit (Eurogen) and sequenced with HiSeq 2500 (Illumina) automated sequencer using Thermo Sequenase Cy5 Dye Terminator Kit. Sequencing of the short 18S rRNA fragment was performed using amplification primers, whereas long amplicons were sequenced with primers $883 \mathrm{~F}, 908 \mathrm{R}, \mathrm{S} 757$ and A757 as described elsewhere (Kostygov et al., 2011; Gerasimov et al., 2012).

\section{Phylogenetic analyses}

The 18S rRNA sequences of trypanosomatids representing the known phylogroups (retrieved from GenBank) were aligned using MEGA X (Molecular Evolutionary Genetic Analysis Version 
10.1.6, www.megasoftware.net) software package (Schwarz et al., 2015). The final file included in total 68 sequences, with Paratrypanosoma confusum as an external group, and contained 2183 positions including indels. Maximum likelihood phylogenetic inference was performed using IQ-TREE software with TIM3e+I+G4 model. The model was selected under Bayesian information criterion by IQ-TREE software (Nguyen et al., 2015). Branch supports were assessed by ultrafast bootstrapping with 1000 replicates (Minh et al., 2013). Bayesian inference was completed in MrBayes 3.2.7 (Ronquist et al., 2012) under GTR + I + G model (4 gamma categories) with analysis run for 1 million generations and sampling of every $1000^{\text {th }}$ of them. Other parameters were set as default.

\section{Results}

INFECTION RATES OF HALYOMORPHA HALYS IN NATURAL POPULATIONS AND LABORATORY LINES

In 2018, we dissected 17 specimens of $H$. halys collected in Sukhumi (Abkhazia), of which 4 were infected with Blastocrithidia spp. $(\approx 24 \%)$. In two cases we observed singular epimastigotes in segments M2 and M3 of the host intestines. Two other specimens of $H$. halys were strongly infected: one in segments M2 and M3, and the other in all the anterior segments of intestine (M1-M3), a large number of Blastocrithidia spp. in all the examined host intestine segments having been with "flagellar cysts" (=straphangers).

Also in 2018, we dissected 24 specimens of $H$. halys collected in Sochi. Only one stink bug $(\approx 4 \%)$ proved to have been infected, the invasion was very strong and affected all the intestine segments: M1M4, ileum and rectum. Epimastigotes with straphangers were found in all the intestine segments. In September 2019, we dissected 56 more stink bugs from Sochi, but did not find flagellates in any of them.

We also dissected 40 and 25 stink bugs $H$. halys from Sochian and Abkhazian laboratory lines, respectively. All the insects from the laboratory lines were not infected.

\section{CUlTIVATION OF BLASTOCRITHIDIA FRUSTRATA SP. N.}

Two xenic cultures of $B$. frustrata were established in TC-100 Insect medium with addition of $10 \%$ fetal bovine serum. The obtained strains were designated as $332 \mathrm{MK}$ (Sochi) and $4 \mathrm{fem}-\mathrm{MK}$ (Sukhumi). Our attempts to clear the cultures of the fungal contamination in the device described previously (Podlipaev and Frolov, 1987) were not successful: when cleared of mycelial and yeast-like fungi, flagellates stopped dividing and died in 1 or 2 weeks. The xenic strains of $B$. frustrata $(332 \mathrm{MK}$ and 4fem-MK) were cryopreserved and stored at -86 ${ }^{\circ} \mathrm{C}$ in the growth medium, supplemented with $10 \%$ DMSO (Sigma-Aldrich, USA). They are currently deposited in the Research Collection of Parasitic Protists at the Zoological Institute of the Russian Academy of Sciences (St. Petersburg, Russia).

\section{Phylogenetic analyses}

SSU rRNA sequences of the isolates from Abkhazia and Sochi (M2, 4femMK and 332MK) proved to be identical to each other. Comparison with the sequences from GenBank revealed that the new species is identical to numerous isolates of $\mathrm{Ch} 7$ and TU63 trypanosomatids except for the isolates PNG32 and PNG73, from which they differ only by one substitution in the variable region V2 of the gene. SSU rRNA gene sequences of new $B$. frustrata isolates have been deposited to the GenBank system under the accession numbers MT636536MT636538.

Maximum likelihood and Bayesian trees based on this marker turned to be generally congruent (Fig. 2). The new species isolates M2, 332MK and 4femMK nested within the Blastocrithidia clade, specifically in the main subclade composed of numerous TU63 isolates and TU Ch7 (Fig. 2). The statistical supports for the relationships within this subclade were rather low, apparently due to small differences in the sequences as demonstrated by short branches.

MorpholOGy OF THE FLAGELLATES $B$. FRUSTRATA SP. N.

\section{Light microscopy}

Two types of epimastigotes can be distinguished based on the smears prepared from the contents of the infected stink bugs' intestines (Table 1). Epimastigotes of the first type are long spindle-like cells with narrow undulating membrane and pointed back end with a filiform outgrowth (Fig. 3, C). The length of flagellum is roughly equivalent to the length of body. Nucleus occupies central position and is displaced to the front end of the cell. Some of these epimastigotes have "flagellar cysts" (Fig. 3, C). 


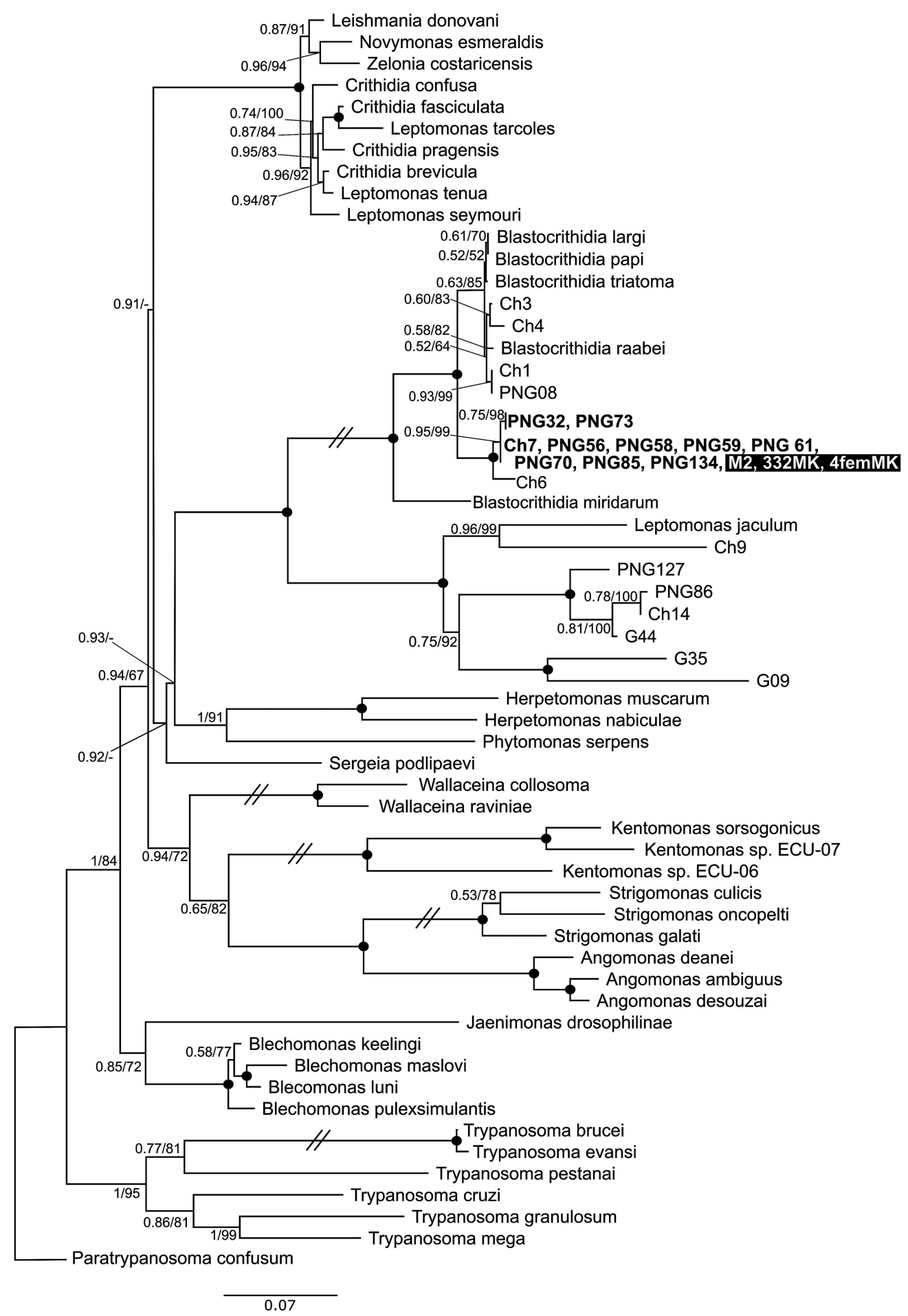

Fig. 2. Maximum likelihood phylogenetic tree reconstructed using $18 \mathrm{~S}$ ribosomal RNA gene sequences. Numbers at nodes indicate posterior probability and bootstrap percentage, respectively. Values less than 0.5 and $50 \%$ are replaced with dashes. Nodes having 1.0 posterior probability, $100 \%$ bootstrap support are marked with black circles. Double-crossed branches are at $50 \%$ of their original lengths. The tree is rooted with the sequence of Paratrypanosoma confusum. The scale bar denotes the number of substitutions per site. The species under study (Blastocrithidia frustrata) are in bold. New isolates of the species are highlighted. Accession numbers of the sequences retrieved from GenBank are available upon request. 


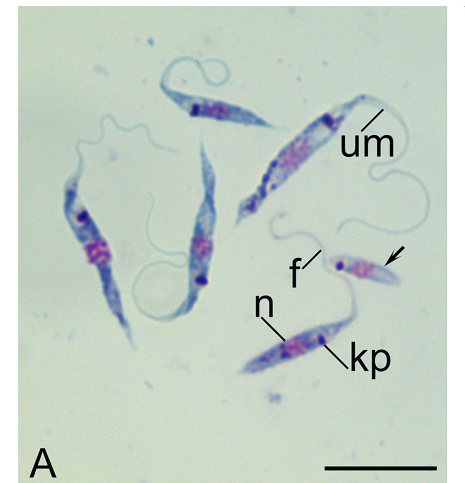

A
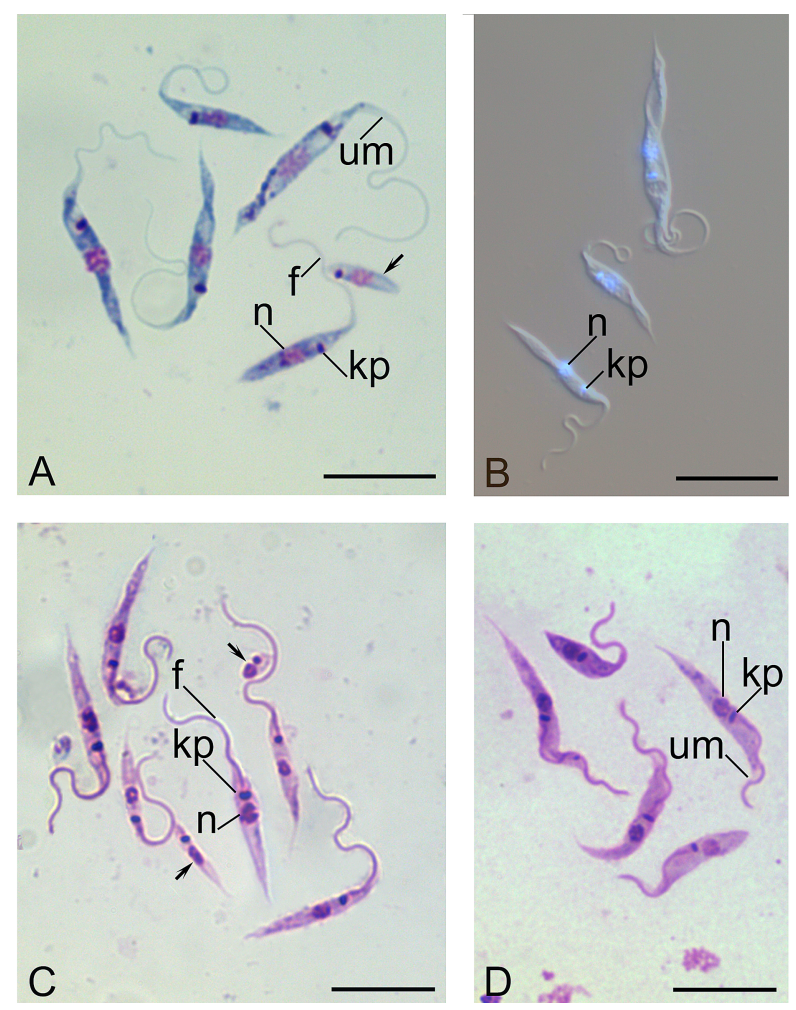

Fig. 3. Light microscopy of Blastocrithidia frustrata sp. n. in the culture and in the host intestine. A, C, D - Giemsa-stained smears; B - overlaid DIC and DAPI. Abbreviations: $\mathrm{f}-$ flagellum; $\mathrm{kp}$ - kinetoplast; $\mathrm{n}$ - nucleus; um - undulating membrane. Arrows points to "cysts". Scale bar: $10 \mu \mathrm{m}$.

Epimastigotes of the second type are cells with wide undulating membrane and very short flagellum or without the latter (Fig. 3, D). The front end is wide, while the back one is tapered and pointed. Nucleus and kinetoplast are often immediately adjacent to each other and located in the center of the cell, being slightly displaced to the back end. In some cases these epimastigotes have "flagellar cysts". Epimastigotes of both types have been found in the "wild" stink bugs (collected in nature), as well as in the insects that were experimentally infected with the laboratory culture of $B$. frustrata.

In the culture, the cells of $B$. frustrata were represented by epimastigotes with narrow and relatively short undulating membrane and filiform tapered back end, with nucleus located approximately in the middle of the cell (Fig. 3, A; 4, A). The length of flagellum was equal to that of body or longer (Table 1). The development of "flagellar cysts" occurred in the culture (Fig. 3, A), especially intensive straphangers formation being found in the older cultures. Having examined DAPI-stained smears, we did not find any DNA-containing structures except for the nucleus and kinetoplast in the cells of $B$. frustrata (Fig. 3, B).

\section{Electron microscopy}

The ultrastructure of $B$. frustrata is generally similar to that of other trypanosomatids. Nucleus is located in the center of the cell or is slightly displaced to the front end (Fig. 4, B). Kinetoplast is found immediately in front of the nucleus and its capsule is electron-dense. Next to kinetoplast there is Golgi complex (Fig. 4, B). Short flagellar pocket opens laterally and is filled with electron-dense contents. The transition zone of flagellum is $370 \mathrm{~nm}$. Outside of flagellar pocket, undulipodium attaches to the well-developed rostrum. At the joint of flagellum and rostrum, a breach in microtubular corset is found (Fig. 4, D), macular hemidesmosomes developing in the contact zone under the plasmalemma of rostrum (Fig. 4, B, C). Alongside flagellum axoneme there is

Table 1. Morphometry of epimastigites and cyst-like amastigotes of Blastocrithidia frustrata sp. $\mathrm{n} .(\mathrm{N}=32)$

\begin{tabular}{|c|c|c|c|c|c|c|c|}
\hline Type of cells & Length & Width & Fagellum & Nucleus & N-A & K-A & $\mathbf{N}-\mathbf{K}$ \\
\hline $\begin{array}{l}\text { Epimastigotes of the first } \\
\text { type in the intestine }\end{array}$ & $\begin{array}{c}15.1 \pm 0.4 \\
(9.9-19.1)\end{array}$ & $\begin{array}{l}1.8 \pm 0.05 \\
(1.5-2.6)\end{array}$ & $\begin{array}{c}13.1 \pm 0.5 \\
(7.3-17.5)\end{array}$ & $\begin{array}{l}2.1 \pm 0.07 \\
(1.4-2.8)\end{array}$ & $\begin{array}{c}6.5 \pm 0.2 \\
(4.7-8.9)\end{array}$ & $\begin{array}{c}4.4 \pm 0.2 \\
(2.6-7.7)\end{array}$ & $\begin{array}{l}1.4 \pm 0.06 \\
(0.7-2.3)\end{array}$ \\
\hline $\begin{array}{l}\text { Epimastigotes of the second } \\
\text { type in the intestine }\end{array}$ & $\begin{array}{c}17.7 \pm 0.6 \\
(11.9-24.0)\end{array}$ & $\begin{array}{l}2.3 \pm 0.07 \\
(1.6-3.0)\end{array}$ & $\begin{array}{l}2.8 \pm 0.5 \\
(0-7.8)\end{array}$ & $\begin{array}{l}1.7 \pm 0.05 \\
(1.3-2.9)\end{array}$ & $\begin{array}{c}9.9 \pm 0.3 \\
(6.7-15.4)\end{array}$ & $\begin{array}{c}9.4 \pm 0.3 \\
(5.1-12.6)\end{array}$ & $\begin{array}{l}0.6 \pm 0.05 \\
(0-1.2)\end{array}$ \\
\hline Cyst-like amastigotes & $\begin{array}{l}2.7 \pm 0.05 \\
(2.2-3.4)\end{array}$ & $\begin{array}{c}1.3 \pm 0.02 \\
(1-1.5)\end{array}$ & & & & & \\
\hline Epimastigotes in the culture & $\begin{array}{c}19.8 \pm 0.7 \\
(13.1-27.4)\end{array}$ & $\begin{array}{l}1.8 \pm 0.06 \\
(1.2-2.7)\end{array}$ & $\begin{array}{c}16.4 \pm 0.8 \\
(9.1-26.2)\end{array}$ & $\begin{array}{l}2.2 \pm 0.06 \\
(1.5-3.1)\end{array}$ & $\begin{array}{c}8.2 \pm 0.3 \\
(3.7-11.4)\end{array}$ & $\begin{array}{c}6.3 \pm 0.3 \\
(2.4-9.7)\end{array}$ & $\begin{array}{c}1.3 \pm 0.1 \\
(0.2-3.5)\end{array}$ \\
\hline
\end{tabular}

Notes: N-A is the distance between the nucleus and the anterior end of the cell. K-A is the distance between the kinetoplast and the anterior end of the cell. $\mathrm{N}-\mathrm{K}$ is the distance between the nucleus and the kinetoplast. All the measurements are in $\mu \mathrm{m}$. 

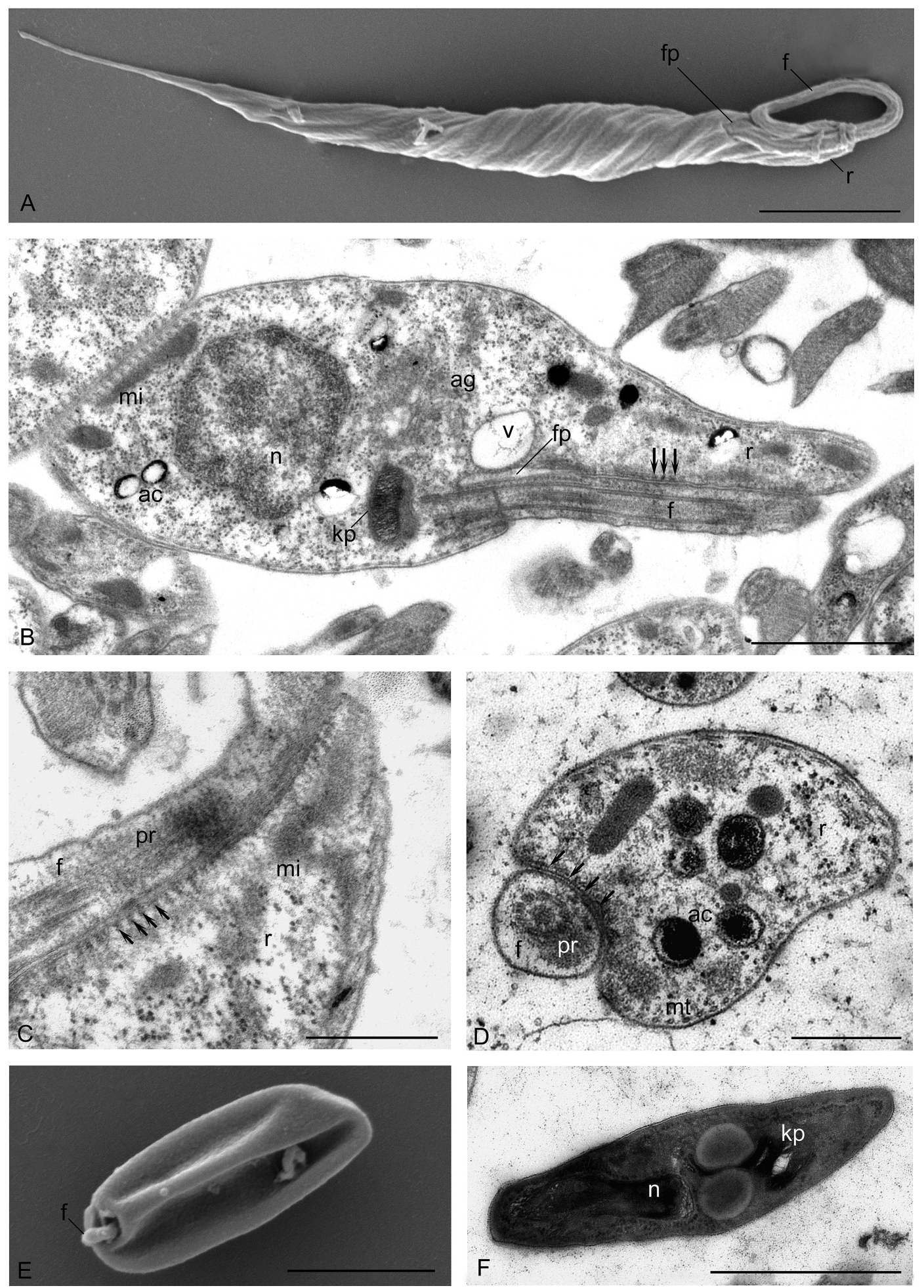

Fig. 4. Morphology of Blastocrithidia frustrata sp. n. (SEM and TEM). A, E - Cells in the culture (SEM); B D, F - cells in the culture and in the host intestine (TEM). A-D - Epimastigote; E, F - "cysts". Abbreviations: ac - acidocalcisomes; ag - Golgi complex; fp - flagellar pocket; mi - mitochondrion; $\mathrm{mt}$-microtubules; $\mathrm{n}$ - nucleus; $\mathrm{pr}$ - paraxial rod; $\mathrm{r}$ - rostrum; $\mathrm{v}$ - vacuole. Arrows points to hemidesmosomes (B, C) and to the breach in the corset microtubules (D). Scale bars: A $-2.5 \mu \mathrm{m} ; \mathrm{B}-1 \mu \mathrm{m} ; \mathrm{C}, \mathrm{D}-0.5 \mu \mathrm{m} ; \mathrm{E}, \mathrm{F}-1.5 \mu \mathrm{m}$. 
paraxial rod, which starts from where undulipodium emerges from flagellar pocket. Mitochondrion forms an extensive network, which occupies the cell's periphery. The branches of mitochondrion penetrate rostrum (Fig. 4, B, C). The electron-dense matrix of mitochondrion conceals cristae. Large number of acidocalcisomes is found in cytoplasm (Fig. 4, B, D). By the side of the flagellar pocket there are vacuoles of various diameters.

"Flagellar cysts" have typical structure. Condensed DNA-containing organelles - the nucleus and kinetoplast - can be distinguished in electron-dense cytoplasm (Fig. 4, F). The layer of subpellicular microtubules under plasmatic membrane is concealed with dense granulous cytoplasm. In the pictures obtained with scanning electron microscope, pre-cyst stages of $B$. frustrata have an easy-to-see rudimental flagellum (Fig. 4, E). Mature "cysts" do not have flagellar complex.

DEVELOPMENT OF $\boldsymbol{B}$. FRUSTRATA IN THE DIGESTIVE SYSTEM OF HALYOMORPHA HALYS

Epimastigotes of B. frustrata have been found in most of the intestine segments of Halyomorpha halys (Fig. 1). Flagellates were often present in all the segments of midgut (M1, M2, M3, M4b and M4) and less often - in ileum and rectum. In hemolymph, salivary glands and Malpighian tubules development stages of $B$. frustrata were not detected.

In the cases of experimental infection, B. frustrata usually did not stay in the anterior segment of midgut (M1). The major depots for the cells of B. frustrata were M2 and M3 segments. The characteristic feature of M2 segment is a great number of extracellular multimembrane layers, which often surround flagellates and isolate them to certain extent from the brush border of host intestinal epithelium (Fig. 5, A). Besides the looselying flagellates, a significant number of attached specimens were found in M2. The distal part of their flagellum widens and takes a peculiar shape, developing protrudences and invaginations and thus interlacing with intestine microvilli (Fig. 5, B). The paraxial rod of such flagella is well-developed. Epimastigotes of B. frustrata do not make desmosome-like contacts with intestinal epithelium. A particularly large amount of epimastigotes concentrates in the intestinal crypts, where the number of extracellular multimembrane layers is minimal. Particular flagellates in M2 can penetrate into the intercellular spaces of intestinal epithelium, disturbing its integrity, and from there get under the basal lamina
(Fig. 5, D). However, we have not found B. frustrata beyond the basal lamina.

In M3 segment of midgut, epimastigotes concentrate around the brush border, tending to fill the intestinal crypts. Many of them attach to host microvilli, as they do in M2 segment (Fig. 5, B), damaging them in part. In epithelium sections without microvilli, epimastigotes attach to the surface of enterocytes with the enlarged apical end of flagellum (Fig. 5, C).

In M4b segment, epimastigotes concentrate around the brush border, hooking on with their flagella to microvilli as described above. Some of the epimastigotes lie loosely in the intestinal lumen, surrounded by extracellular membranes and secretion.

M4 segment is a specialized symbiont-containing intestinal segment. Around the central canal, which is an extension of M4b, there are four lines of crypts where symbiotic bacteria are localized. In this gut segment, the cells of $B$. frustrata have been found only in the central canal.

In hindgut, B. frustrata frequently formed significant clusters on the surface of epithelium. Many epimastigotes also had straphangers.

EXPERIMENTAL INFECTION OF $H$. HALYS WITH $B$. FRUSTRATA CULTURE (STRAIN $332 \mathrm{MK}$ )

All the experiments were carried out with laboratory lines of $H$. halys (Sochi and Abkhazia). After females had laid eggs, the clutches were isolated and put into clean cages, while the insects were dissected and all the segments of their intestine microscoped. In the cases of absence of flagellates in the digestive system of females, their offspring were later used in the infection experiments.

Nymphs of 3 to 5 ages and imagoes were infected with the xenic culture $332 \mathrm{MK}$. We used 75 specimens in our experiment and 50 as a control group. For two days before the experiment, the stink bugs had been kept in sterile cages without food and water; after that we put into the cages drinking troughs with the flagellate culture and left them for $24 \mathrm{~h}$. Meanwhile the control group was given troughs with clean water. After $24 \mathrm{~h}$ the stink bugs were given food and water. Then over the period of 37 days they were dissected every 2 or 3 days, 2 to 4 specimens from each of the two groups every time. Of 75 specimens from the experimental group of $H$. halys, only 32 were infected by $B$. frustrata flagellates. On the second or third days we could find singular epimastigotes in the anterior intestinal segments M1 

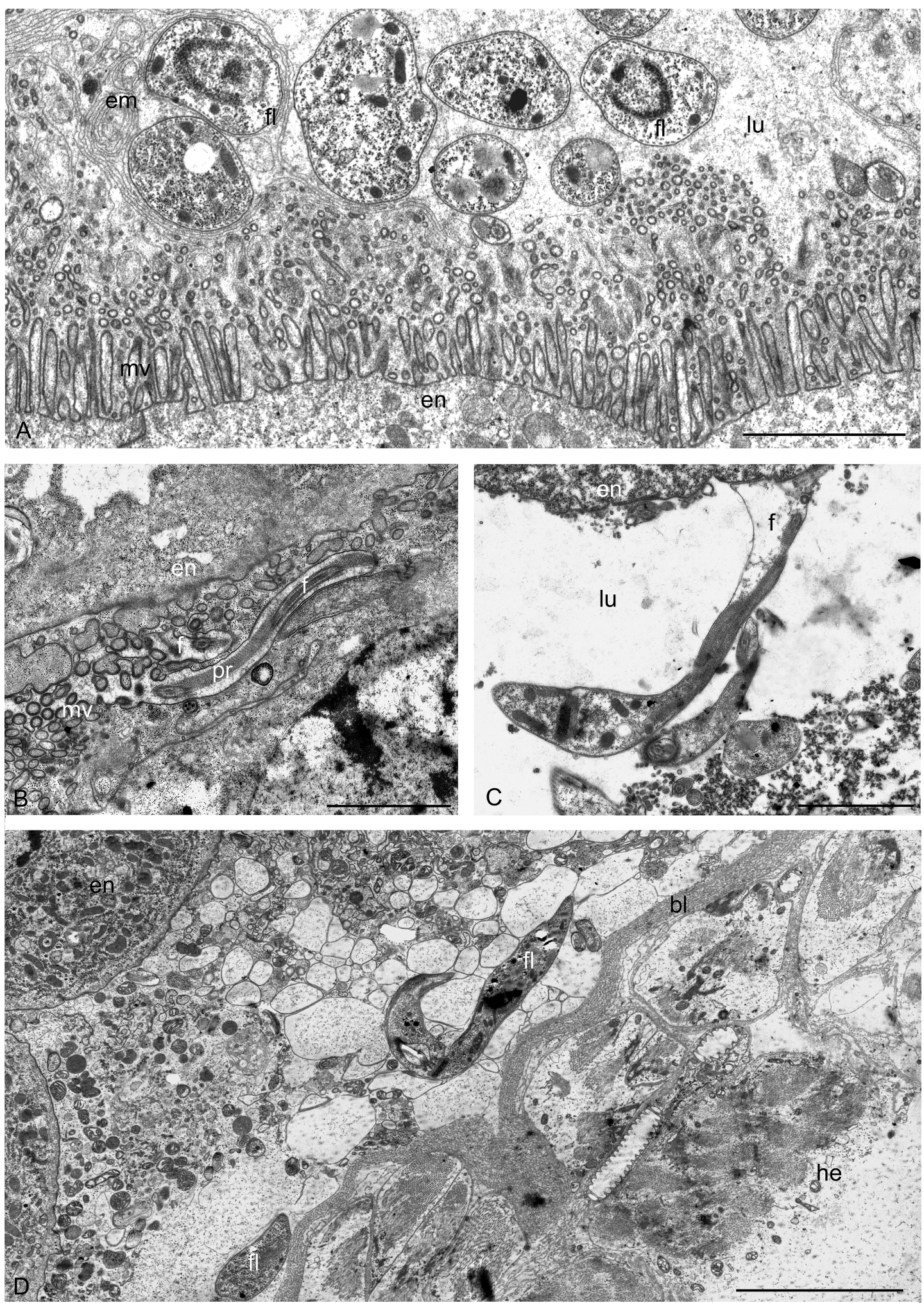

Fig. 5. Blastocrithidia frustrata sp. $\mathrm{n}$ in the host midgut. A - Flagellates in the lumen of midgut (M2); A, C attachment of flagellates to enterocytes; D - flagellates under basal lamina (M2). Abbreviations: bl - basal lamina; em - extracellular membrane layers (ECML); en - enterocyte; $\mathrm{f}$ - flagellum; fl - flagellate; he - hemocoel; lu - gut lumen; mv - microvilli; pr - paraxial rod. Scale bars: A-C $-2 \mu \mathrm{m}$; D $-5 \mu \mathrm{m}$. 
and M2. In M3 flagellates appeared on the $6^{\text {th }}$ or $7^{\text {th }}$ day, and in M4 - only on the $20^{\text {th }}$ day. In ileum and rectum, flagellates were found in 8 specimens dissected after 28 days since the beginning of the experiment. The dissection of all the 50 specimens from the control group of $H$. halys was carried out at the same time and proved the absence of trypanosomatids in the digestive organs of hosts.

POSSIBILITY OF VERTICAL TRANSMISSION OF $\boldsymbol{B}$. FRUSTRATA

Females of brown marmorated stink bug (12 specimens) were infected with the $B$. frustrata culture, as described above, and put into individual cages. After 7 to 10 days we put uninfected males into the cages with infected females. After mating and egg-laying, the clutches were isolated and put into clean cages. After that the males and females were dissected and all their intestinal segments microscoped (Fig. 1). In 5 of the 12 infected females we found flagellates with "cysts" in hindgut, while there was no invasion in any of the 12 males. The nymphs and imagoes hatched from the infected females' clutches were also dissected and all their intestinal sections examined. In total, we have dissected 45 nymphs of 2 to 5 ages and 38 imagoes. All the 83 specimens turned to be not infected.

Some of the eggs from the clutches obtained from the infected females were put into 6 test tubes with TC-100 Insect medium supplemented with $10 \%$ Fetal Bovine Serum and an antibiotic. After 54 days we found epimastigotes in one of the tubes.

EXPERIMENTS ON THE POSSIBILITY OF HORIZONTAL TRANSMISSION OF $\boldsymbol{B}$. FRUSTRATA IN LABORATORY CULTURES OF H. HALYS

\section{Through contaminated substrate}

We put 20 uninfected stink bugs - nymphs of 3 to 5 ages and imagoes - into the cages where $H$. halys infected by the $B$. frustrata culture had been earlier kept. Between the $10^{\text {th }}$ and $25^{\text {th }}$ day after the beginning of the experiment the insects were dissected. The experiment was repeated twice. In all cases the results were negative: none of the stink bugs was infected with trypanosomatids.

\section{From infected specimens to uninfected ones}

We put 20 uninfected nymphs of $H$. halys of 3 to 5 ages and 35 uninfected imago together with 55 specimens of $H$. halys infected with the $B$. frustrata culture. The infected stink bugs were previously marked by cutting off one antenna. The stink bugs from both groups were dissected between the $10^{\text {th }}$ and $30^{\text {th }}$ day since the beginning of the experiment. As a result, we found invasion and "cyst" development in 39 of the 55 specimens of $H$. halys infected by B. frustrata $(\approx 70 \%)$. Meanwhile of the 55 specimens put together with them to be infected only 1 adult male dissected on the 13th day after the beginning of the experiment proved to have been infected by B. frustrata $(\approx 2 \%)$.

\section{Taxonomic summary}

Class Kinetoplastea Honigberg, 1963

Subclass Metakinetoplastina Vickerman, 2004

Order Trypanosomatida Kent, 1880

Family Trypanosomatidae Doflein, 1901

Genus Blastocrithidia Laird, 1959

Blastocrithidia frustrata Malysheva, Ganyukova et Frolov sp. n.

Morphology: found in host intestine in two forms of epimastigotes, as well as in cyst-like amastigotes. Epimastigotes (1) with narrow undulating membrane and long flagellum; length 9.9 to $19.1 \mu \mathrm{m}$, flagellum 7.3 to $17.5 \mu \mathrm{m}$; (2) with wide undulating membrane and short flagellum or without the latter; length 11.9 to $24 \mu \mathrm{m}$, flagellum 0 to $7.8 \mu \mathrm{m}$.

Gene sequences: the species can be identified by the sequences of 18S rRNA (GenBank accession numbers: MT636536-MT636538).

Type host: Halyomorpha halys (Stel) (Hemiptera: Pentatomidae).

Location within host: all parts of intestine.

Type locality: Russia: the Krasnodar Territory,

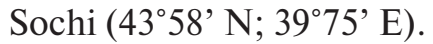

Other localities: Sukhumi (Abkhazia) $\left(43^{\circ} 00^{\prime} \mathrm{N}\right.$; $\left.41^{\circ} 00^{\prime} \mathrm{E}\right)$.

Type material: Giemsa-stained slide 332MK-M2 (hapantotype) deposited in the research collection of Parasitic Protists at the Zoological Institute RAS (St. Petersburg, Russia), along with the additional smear 4fem-MK-M2 (from Abkhazia) and type cultures $332 \mathrm{MK}$ and $4 \mathrm{fem}-\mathrm{MK}$.

Etymology: the species name frustrata has been derived from the Latin noun "frustrata", which means "disappointment". The name emphasizes that our attempt to find parasites specific for the highly invasive species Halyomorpha halys has been unsuccessful. 


\section{Discussion}

The new species of monoxenous trypanosomatids $B$. frustrata described in this article has been found in two populations of brown marmorated stink bugs in the Krasnodar Territory (Krasnodarskiy Krai), Russia, and in Abkhazia. In terms of phylogeny, the isolates of the new species 332MK (Sochi) and 4 fem-MK (Sukhumi) were $100 \%$ identical to each other and to numerous isolates $\mathrm{Ch} 7$ distinguished among the representatives of 4 different families of Hemiptera in China (Belostomatidae, Coreidae, Gerridae and Pentatomidae), as well as to 7 isolates TU63 from 3 families of Hemiptera (Coreidae, Pyrrhocoridae and Reduviidae) in Papua New Guinea (Votýka et al., 2010; Králová et al., 2019). Currently, B. frustrata has been detected in 13 species of Hemiptera from 6 different families in China, Papua New Guinea and Russia. Meanwhile, the question whether or not all the species of hosts, in which isolates of $B$. frustrata have been found, are specific for them remains open. Potentially wide host-specificity of the new species has been already discussed earlier (Králová et al., 2019). However, to prove this specificity one would have to demonstrate a steady transmission of the parasite between the specimens of a particular species of hosts (McGee and Cosgrove, 1980). Only such an approach would allow us to exclude the possibility of mistakes, most of which might stem from the cases of non-specific or transitory invasions (Yurchenko et al., 2006; Maslov et al., 2007; Chandler and James, 2013; Týč et al., 2013).

In our research, we have not succeeded in overwhelmingly proving the specificity of the relations between $B$. frustrata and $H$. halys. The infection of $H$. halys with the laboratory culture of $B$. frustrata was generally unstable. As part of different experiments, from $40 \%$ to $70 \%$ of the insects were infected. The success rate of the infection did not depend on the age of the stink bugs, as we obtained similar results for both imagoes and nymphs. $B$. frustrata demonstrated long development of the invasion: in hindgut, epimastigotes appeared only after 20 days since the beginning of the infection. However, the transmission stages of $B$. frustrata, i.e. "flagellar cysts", were detected early in the course of the infection process, their development occurring in all the infected intestinal segments of $H$. halys. It is possible, though, that at least in the anterior segments of intestine this could have been a result of the ongoing cytokinesis of culture stages, since the process of "cyst" development runs constantly in cultures of B. frustrata.

The experiments on the vertical transmission of the invasion proved to be unsuccessful: of the 83 dissected stink bugs, which had hatched from the infected females' clutches, none was infected. Notably, the surface of the eggs laid by the infected females was certainly contaminated by the "cysts" of $B$. frustrata, since in one of the 6 test tubes with nutrient medium, where the eggs of $H$. halys had been put, the excystation of the flagellates occurred. It is a common knowledge that nymphs of the first age of Halyomorpha halys, just as the majority of other members of Pentatomidae, stay on the clutch for the period between hatching and the first ecdysis and keep probing the surface of the eggs (Lee et al., 2013; Taylor et al., 2014). Such a behavior protects them from low temperatures, drying out and predators, and helps them to retain on the plant (Lockwood and Story, 1986), as well as to obtain specific prokaryotic symbionts (in the case of $H$. halys, those are Candidatus Pantoea carbekii) (Bansal et al., 2014; Taylor et al., 2014; Kenyon et al., 2015; Otero-Bravo and Sabree, 2018). Therefore, in course of our experiments "cysts" of $B$. frustrata were supposed to get into the digestive system of $H$. halys nymphs along with prokaryotic symbionts. However, their development in the nymphs did not occur. This might have been due to the absence of any enzymes required for the excystation of $B$. frustrata in this host species, or perhaps the process of excystation itself was blocked by the hosts' protective mechanisms.

As for the horizontal transmission, our experiments have demonstrated that, although being possible, it appears to be more an exception than a rule. Only in one case we observed the transmission of the invasion from an infected female to an uninfected male. In all the other experiments the results were negative.

It is known that successful diversification of monoxenous trypanosomatids is facilitated by their insect hosts' feeding and behavior strategies, such as predation, cannibalism, necrophagy, coprophagy, feeding on organic substrates contaminated with feces of infected insects, clustering around sources of food and colonial way of life (McGee and Cos-grove, 1980; Maslov et al., 2013; Lukeš et al., 2014, 2018; Frolov, 2016). For the successful development of a parasite, its life cycle needs to be associated with (McGee and Cosgrove, 1980), or in some cases even synchronized with that of the 
host, as it has been observed in B. papi (Frolov et al., 2018). The biological features of brown marmorated stink bugs apparently do not help their infection with trypanosomatids. Such phenomena as predation and necrophagy are not characteristic of the phytophagous $H$. halys (Chambers et al., 2019), while cannibalism has been detected only in laboratory cultures and exclusively on recently molted individuals (Medal et al., 2012; Chambers et al., 2019). Egg cannibalism (feeding of nymphs on eggs) most likely also does not occur due to the nymphs' synchronous hatching (Endo and Numata, 2020). Brown marmorated stink bugs feed exclusively on green parts of plants or fruits. Insects feeding on the ground, unlike those feeding on plant surfaces, are considered to have higher probability of contamination with feces of other insects containing infectious parasite stages (Králová et al., 2019). Phytophagous insects with piercing and sucking mouthparts have low chances of being infected through contaminated substrates in the process of piercing plant epidermis with their beak (McGee and Cosgrove, 1980).

Even given the conservatism of the ultrathin organization typical of trypanosomatids in general, we have managed to find a number of characteristic features of $B$. frustrata distinguishing the new species from the majority of monoxenous flagellates. Thus, the so-called FAZ (flagellum attachment zone), characteristic of Trypanosoma spp. but absent in monoxenous representatives of the family, is to the fullest extent possibly present in $B$. frustrata (Vickerman, 1969; Brooks, 1978; Sunter and Gull, 2016). FAZ is a complex structure, which develops with the involvement of cytoskeleton, membrane elements of flagellum and rostrum of trypanosomatid cells. FAZ lies between the point of flagellum emergence from flagellar pocket and the front end of the cell. Trypanosome FAZ is characterized by the following features (Brooks, 1978; Sunter and Gull, 2016): (1) presence of a breach in microtubular corset at the joint of flagellum and plasmalemma of rostrum; (2) macular desmosomes found in this area; (3) specialized quartet of microtubules closely connected to endoplasmic reticulum, which wedges between them. In the longitudinal section of $B$. frustrata rostrum, under plasmalemma, one can clearly see the regularly situated hemidesmosomes. In the transversal sections of rostrum, sub-membrane microtubules are absent in this zone. The breach in microtubular corset at the joint of flagellum and rostrum has been earlier described in B. papi
(Frolov et al., 2017), but it has not been found in other Blastocrithidia spp. (Frolov and Karpov, 1995). However, the contacts of numerous macular hemidesmosomes between flagellar membranes and flagellar pocket have been detected in the representatives of "jaculum" clade affined with the genus Blastocrithidia, i.e. in Leptomonas jaculum and L. oncopelti during the development of the socalled "hidden" undulating membrane (Frolov and Skarlato, 1989; Frolov et al., 1991; Malysheva et al., 2006; Kostygov and Frolov, 2007).

The existence of the two morphs of epimastigotes of $B$. frustrata in $H$. halys intestine, which we have described in this paper, appears to be of significant interest. It correlates with the earlier obtained data for the isolates $\mathrm{Ch} 7$, which are also found in host intestine as epimastigotes widely varying in size (Votýpka et al., 2010). A similar dimorphism has been recently described in $B$. raabei from different intestinal segments of Coreus marginatus (Frolov et al., 2020).

$B$. frustrata does not demonstrate any preferences in the localization of parasites in host digestive system. The distribution of trypanosomatids was homogeneous throughout midgut. Flagellates B. culicis behave in a similar way in the case of non-specific invasions of Aedes aegypti mosquitos (Corrêa-da-Silva, 2006). Like epimastigotes of $B$. familiaris, B. miridarum and B. papi, those of $B$. frustrata hook on with their widened and branched flagellum tips to the microvilli of intestine enterocytes (Tieszen et al., 1986; Podlipaev and Frolov, 1987; Frolov et al., 2017).

The perforation of intestine epithelium and penetration of $B$. frustrata under the basal lamina of $H$. halys remain difficult to explain. Such a behavior of flagellates and their consequent emission into hemolymph and penetration into host salivary glands are typical of a number of dixenous trypanosomatids of the Phytomonas and Trypanosoma genera (Tobie 1965; Jankevicius et al., 1989; Hecker et al., 1990; Nascimento et al., 2010; Frolov et al., 2016, 2019). For monoxenous trypanosomatids, this phenomenon has been earlier registered only in B. raabei (Frolov et al., 2020) and B. culicis (Corrêa-da-Silva et al., 2006). The peculiar life cycle of $B$. raabei is related to the features of the host (Coreus marginatus) intestine structure and the need for the parasites to overpass a particular valvule (constrictor region), which is characteristic of many phytophagous Pentatomorpha and separates the anterior midgut segments from the specialized 
symbiont-containing host intestine segment M4 (Ohbayashia et al., 2015). In B. culicis, a continuous infection can result in degradation of $A$. aegypti midgut and appearance of protozoa under basal lamina and in hemocoel (Corrêa-da-Silva et. al., 2006).

The process of cyst formation in $B$. frustrata is not confined to a particular section of $H$. halys digestive system. "Flagellar cysts" develop both in mid- and hindgut of the host. A similar situation can be observed in B. raabei, which forms "cysts" in M4 midgut segment and rectum of stink bugs Coreus marginatus (Frolov et al., 2020). In B. triatomae and Leptomonas wallacei, by contrast, "cyst" development occurs exclusively in their hosts' rectum (Schaub et al., 1989; Dias et al., 2014), while in B. papi, "flagellar cysts" develop in Malpighian tubules of Pyrrhocoris apterus stink bugs (Frolov et al., 2016, 2018).

\section{Conclusion}

Blastocrithidia frustrata described in this article represents a widely spread species of trypanosomatids, which has been so far found in hemipteran insects in China, Papua New Guinea and Russia. A specific host of these trypanosomatids still remains unrevealed. Our research has demonstrated that brown marmorated stink bug $H$. halys cannot be considered as such, although it can be infected by B. frustrata and play a part in the dispersion of these flagellates during limited time periods. B. frustrata's continuous development in the host and ability to produce transmission stages imitate a "normal" course of its life cycle in $H$. halys, but the absence of a stable mechanism of transmission of the parasites between hosts limits the potential of the existence of this host-parasite system. It seems highly likely that some of the hosts of $B$. frustrata revealed through the method of barcoding of trypanosomatids in China and Papua New Guinea are also not specific for this species. This primarily refers to predatory stink bugs from the families Belostomatidae, Gerridae and Reduviidae. It is known that predators often act as non-specific hosts for trypanosomatids, obtaining those from their prey. As all the other known cases of $B$. frustrata discoveries are associated with the representatives of 3 families of phytophagous Pentatomorpha, it can be assumed that the specific hosts of these trypanosomatids might belong to this particular group. In any case, the speculation about the possibility of "occasional" infection of predators from their prey, phytophagous stink bugs, appears to be more plausible than an opposite statement. Among the phytophagous hosts, the representatives of Coreidae family, in which high rates of invasion have been detected in China (Ochrochira sp.) and Papua New Guinea (Gralliclava irianensis) (Králová et al., 2019), seem to be the most likely candidates for the role of the specific hosts of B. frustrata.

\section{Acknowledgements}

This work was supported by the Russian Science Foundation (http://www.rscf.ru) grant No 18-14-00134 to MNM, AIG and AOF (light and electron microscopy, experimental infection, molecular characterization of B. frustrata samples, phylogenetic analyses), and the State Assignment for the Zoological Institute RAS AAAA-A19-119020690109-2 to MNM, AIG and AOF (material collection). The research was completed using equipment of the Core Facilities Centre "Taxon" at the Zoological Institute, Russian Academy of Sciences (St. Petersburg, Russia).

\section{References}

Akhoundi M., Kuhls K., Cannet A., Votýpka J., Marty P., Delaunay P., et al. 2016. A historical overview of the classification, evolution, and dispersion of Leishmania parasites and sandflies. PLoS Negl. Trop. Dis. 10, e0004349.

Arnold K. 2009. Halyomorpha halys (Stål, 1855), eine fur die europaische Fauna neu nachgewiesene Wanzenart (Insecta: Heteroptera: Pentatomidae: Cappaeini). Mitt. Thuringer Entomol. 16, 19.

Bansal R., Michel A. and Sabree Z. 2014. The crypt-dwelling primary bacterial symbiont of the polyphagous pentatomid pest Halyomorpha halys (Hemiptera: Pentatomidae). Environ. Entomol. 43, 617-625.

Brooks A. 1978. Ultrastructure of the flagellar attachment site in three species of trypanosomatids. Trans. Am. Micr. Soc. 97 (3), 287-296.

Callot H. and Brua C. 2013. Halyomorpha halys (Stål, 1855), la Punaise diabolique, nouvelle espece pour la faune de France (Heteroptera Pentatomidae). L'Entomologiste. 69, 69-71.

Camargo E.P. 1999. Phytomonas and other trypanosomatid parasites of plants and fruit. Adv. Parasitol. 42, 29-112. 
Cesari M., Maistrello L., Ganzerli F., Dioli P., Rebecchi L. and Guidetti R. 2014. A pest alien invasion in progress: potential pathways of origin of the brown marmorated stink bug Halyomorpha halys populations in Italy. J. Pest. Sci. doi:10.1007/ s10340-014-0634-y.

Chambers B., Leskey T., Pearce A. and Kuhlar T. 2019. Responses of overwintering Halyomorpha halys (Hemiptera: Pentatomidae) to dead conspecifics. J. Econ. Entom. 112 (3), 1489- 1492.

Chandler J.A. and James P.M. 2013. Discovery of trypanosomatid parasites in globally distributed Drosophila species. PLoS ONE. 8, e61937.

Chicharro C. and Alvar J. 2003. Lower trypanosomatids in HIV/AIDS patients. Ann. Trop. Med. Parasitol. Oct; 97 Suppl. 1, 75-78.

Corrêa-da-Silva M., Fampa P., Lessa L., dos Reis Silva E., dos Santos Mallet J.R., Saraiva E.M.B. and Motta M.C.M. 2006. Colonization of Aedes aegypti midgut by the endosymbiont-bearing trypanosomatid Blastocrithidia culicis. Parasitol. Res. 99, 384-391.

Dedet J.P., Roche B., Pratlong F., Cales-Quist D., Jouannelle J., Benichou J.C. and Huerre M. 1995. Diffuse cutaneous infection caused by a presumed monoxenous trypanosomatid in a patient Infected with HIV. Trans. R. Soc. Trop. Med. Hyg. 89 (6), 644-646.

Dedet J.P. and Pratlong F.J. 2000. Leishmania, Trypanosoma and monoxenous trypanosomatids as emerging opportunistic agents. J. Eukar. Microbiol. 47 (1), 37-39.

Dias F. de A., Vasconcellos L.R., Romeiro A., Attias M., Souto-Padron T.C. and Lopes A.H. 2014. Transovum transmission of trypanosomatid cysts in the Milkweed bug, Oncopeltus fasciatus. PLoS ONE. 9 (9), e108746.

Endo J. and Numata H. 2020. Synchronized hatching as a possible strategy to avoid sibling cannibalism in stink bugs. Behavioral Ecology and Sociobiology. 74, 16.

Fogain R. and Graff S. 2011. First records of the invasive pest, Halyomarpha halys (Hemiptera: Pentatomidae) in Ontario and Quebec. J. Ent. Soc. Ont. 142, 45-48.

Frolov A.O. 2016. Trypanosomatids (Kinetoplastea: Trypanosomatida) and insects (Insecta): patterns of co-evolution and diversification of the host-parasite systems. Proc. Zool. Inst. RAS. Suppl. 4, 16-74 (in Russian with English summary).

Frolov A.O. and Skarlato S.O. 1989. Electronmicroscopical study of the flagellates Leptomonas jaculum in the midgut of a hemipteran Nepa cinerea. Parazitologiya. 23 (5), 383-389 (in Russian with English summary).

Frolov A.O., Skarlato S.O. and Shaglina E.G. 1991. Morphology of the cyst-like cells in flagellates Leptomonas jaculum. Tsitologiya. 33, 55-58 (in Russian with English summary).

Frolov A.O. and Karpov S.A. 1995. Comparative morphology of kinetoplastids. Tsitologiya. 37, 1072-1096 (in Russian with English summary).

Frolov A.O., Malysheva M.N. and Kostygov A.Y. 2015. Transformations of life cycles in the evolutionary history of trypanosomatids. (Macrotransformations). Parazitologiya. 49, 233-256 (in Russian with English summary).

Frolov A.O., Malysheva M.N., Yurchenko V. and Kostygov A.Yu. 2016. Back to monoxeny: Phytomonas nordicus descended from dixenous plant parasites. Eur. J. Protistol. 52, 1-10.

Frolov A.O., Malysheva M.N., Ganyukova A.I., Yurchenko V. and Kostygov A.Y. 2017. Life cycle of Blastocrithidia papi sp. n. (Kinetoplastea, Trypanosomatidae) in Pyrrhocoris apterus (Hemiptera, Pyrrhocoridae). Eur. J. Protistol. 57, 85-98.

Frolov A.O., Malysheva M.N., Ganyukova A.I., Yurchenko V and Kostygov A.Y. 2018. Obligate development of Blastocrithidia papi (Trypanosomatidae) in the Malpighian tubules of Pyrrhocoris apterus (Hemiptera) and coordination of host-parasite life cycles. PLoS ONE. 13 (9), e0204467.

Frolov A.O., Malysheva M.N., Ganyukova A.I., Spodareva V.V., Yurchenko V. and Kostygov A.Y. 2019. Development of Phytomonas lipae sp. n. (Kinetoplastea: Trypanosomatidae) in the true bug Coreus marginatus (Heteroptera: Coreidae) into the evolution of the life cycles in the genus Phytomonas. PLoS ONE. 14 (4), e0214484.

Frolov A.O., Malysheva M.N., Ganyukova A.I., Spodareva V.V., Králová J., Yurchenko V. and Kostygov A.Y. 2020. If host is refractory, insistent parasite goes berserk: Trypanosomatid Blastocrithidia raabei in the dock bug Coreus marginatus. PLoS ONE. 15 (1), e0227832.

Ganyukova A.I., Malysheva M.N., Smirnov P.A. and Frolov A.O. 2019. Crithidia dobrovolskii sp. n. (Kinetoplastida: Trypanosomatidae) from parasitoid fly Lypha dubia (Diptera: Tachinidae): morphology and phylogenetic position. Protistology. 13 (4), 206-214.

Gapon D.A. 2016. First records of the brown marmorated stink bug Halyomorpha halys (Stål, 1855) 
(Heteroptera, Pentatomidae) in Russia, Abkhazia and Georgia. Entomol. Rev. 96 (8), 1086-1088.

Gariepy T.D., Fraser H. and Scott-Dupreea C.D. 2014. Brown marmorated stink bug (Hemiptera: Pentatomidae) in Canada: recent establishment, occurrence, and pest status in southern Ontario. Can. Entomol. doi:10.4039/tce.2014.4.

Garin Y.J., Sulahian A., Mйneceur P., Pratlong F., Prina E., Gangneux J., Dedet J.P. and Derouin F. 2001. Experimental pathogenicity of a presumed monoxenous trypanosomatid isolated from humans in a murine model. J. Eukar. Microbiol. 48 (2), 170-176.

Gerasimov E.S., Kostygov A.Y., Yan S. and Kolesnikov A.A. 2012. From cryptogene to gene? ND8 editing domain reduction in insect trypanosomatids. Eur. J. Protistol. 48, 185-193.

Ghosh S., Banerjee P., Sarkar A., Datta S. and Chatterjee M. 2012. Coinfection of Leptomonas seymouri and Leishmania donovani in Indian leishmaniasis. J. Clin. Microbiol. 50 (8), 2774-2778.

Hamilton P.T., Votýpka J., Dostalova A., Yurchenko V., Bird N.H., Lukeš J., Lemaitre B. and Perlman S.J. 2015. Infection dynamics and immune response in a newly described Drosophilatrypanosomatid association. MBio. 6, e01356e01315.

Haye T., Gariepy T., Hoelmer K., Rossi J.P., Streito J.-C., Tassus X. and Desneux N. 2015. Range expansion of the invasive brown marmorated stinkbug, Halyomorpha halys: an increasing threat to field, fruit and vegetable crops worldwide. J. Pest. Sci. 88, 665-673.

Hecker H., Schwarzenbach M. and Rudin W. 1990. Development and interactions of Trypanosoma rangeli in and with the reduviid bug Rhodnius prolixus. Parasitol. Res. 76, 311-318.

Heckmann R. 2012. Erster Nachweis von Halyomorpha halys (Stål, 1855) (Heteroptera: Pentatomidae) fur Deutschland.Heteropteron. Heteropteron. 36, 17-18.

Hoare C.A. 1972. The trypanosomes of mammals. Oxford: Blackwell Scientific Publications.

Hoebeke E.R. and Carter M.E. 2003. Halyomorpha halys (Stål) (Heteroptera: Pentatomidae): a polyphagous plant pest from Asia newly detected in North America. Proc. Entomol. Soc. Wash. 105 (1), 225-237.

Jankevicius J.V., Jankevicius S.I., Campaner M., Conchon I., Maeda L.A., Teixeira M.M.G., Freymuller E. and Camargo E.P. 1989. Life cycle and culturing of Phytomonas serpens (Gibbs), a trypanosomatid parasite of tomatoes. J. Protozool. 36, 265-271.

Jaskowska E., Butler C., Preston G. and Kelly S. 2015. Phytomonas: trypanosomatids adapted to plant environments. PLoS Pathog. 11 (1), e1004484.

Kenyon L., Meulia T. and Sabree Z. 2015. Habitat visualization and genomic analysis of " $\mathrm{Can}$ didatus Pantoea carbekii," the primary symbiont of the brown marmorated stink bug. Genome Biol. Evol. 7 (2), 620-635.

Kitajima E.W. 1986. Flagellate protozoon associated with poor development of the root system of Cassava in the Espirito Santo State, Brazil. Phytopathology. 76, 638 .

Kostygov A.Y. and Frolov A.O. 2007. Leptomonasjaculum (Leger, 1902) Woodcock 1914: a leptomonas or a blastocrithidia? Parazitologiya. 41, 126136 (in Russian with English summary).

Kostygov A.Y., Malysheva M.N. and Frolov A.O., 2011. Investigation of causes of the conflict between taxonomy and molecular phylogeny of trypanosomatids by the example of Leptomonas nabiculae Podlipaev, 1987. Parazitologiya. 45, 409424 (in Russian with English summary).

Králová J., Grybchuk-Ieremenko A., Votýpka J., Novotný V., Kment P., Lukeљs J., Yurchenko V. and Kostygov A.Y. 2019. Insect trypanosomatids in Papua New Guinea: high endemism and diversity. Int. J. Parasitol. 49, 1075-1086.

Lee D.H., Short B.D., Joseph S.V., Bergh J.C. and Leskey T.C. 2013. Review of the biology, ecology, and management of Halyomorpha halys (Hemiptera: Pentatomidae) in China, Japan, and the Republic of Korea. Environ. Entomol. 42 (4), 627-641.

Lockwood J.A. and Story R.N. 1986. The diurnal ethology of the southern green stink bug, Nezara viridula (L.), in cowpeas. J. Ga. Entomol. Soc. 21, 175-184.

Lukeš J., Skalický T., Týc J., Votýpka J. and Yurchenko V. 2014. Evolution of parasitism in kinetoplastid flagellates. Mol. Biochem. Parasit. 195, 115-122.

Lukeš J., Butenko A., Hashimi H., Maslov D.A., Votýpka J. and Yurchenko V. 2018. Trypanosomatids are much more than just trypanosomes: clues from the expanded family tree. Trends. Parasitol. 34, 466- 480 .

Malysheva M.N., Frolov A.O. and Skarlato S.O. 2006. Development of cyst-like cells of the 
flagellate Leptomonas oncopelti in the midgut of the hemipteran Oncopeltus fasciatus. Tsitologiya. 48, 723-733 (in Russian with English summary).

Maslov D.A., Luke љs J., Jirku M. and Simpson L. 1996. Phylogeny of trypanosomes as inferred from the small and large subunit rRNAs: implications for the evolution of parasitism in the trypanosomatid protozoa. Mol. Biochem. Parasit. 75 (2), 197-205.

Maslov D.A., Westenberger S.J., Xu X., Campbell D.A. and Sturm N.R. 2007. Discovery and barcoding by analysis of Spliced Leader RNA gene sequences of new isolates of Trypanosomatidae from Heteroptera in Costa Rica and Ecuador. J. Eukar. Microbiol. 54, 57-65.

Maslov D., Votýpka J., Yurchenko V. and Lukeš J. 2013. Diversity and phylogeny of insect trypanosomatids: all that is hidden shall be revealed. Trends Parasitol. 29 (1), 43-52.

Maslov D.A., Opperdoes F.R., Kostygov A.Y., Hashimi H., Luke $s$ J. and Yurchenko V. 2019. Recent advances in trypanosomatid research: genome organisation, expression, metabolism, taxonomy and evolution. Parasitology. 146, 1-27.

McGee R. and Cosgrove W. 1980. Biology and physiology of the lower Trypanosomatidae. Microbiol. Rev. 44 (1), 140-173.

Medal J., Smith T., Fox A., Santa Cruz A., Poplin A. and Hodges A. 2012. Rearing the brown marmorated stink bug Halyomorpha halys (Heteroptera: Pentatomidae). Florida Entomol. 95, 800-802.

Milonas P.G. and Partsinevelos G.K. 2014. First report of brown marmorated stink bug Halyomorpha halys Stål (Hemiptera: Pentatomidae) in Greece. EPPO Bull. 44, 183-186.

Minh B.Q., Nguyen M.A. and von Haeseler A. 2013. Ultrafast approximation for phylogenetic bootstrap. Mol. Biol. Evol. 30, 1188-1195.

Mityushev I.M. 2016. First record of Halyomorpha halys detection in Russia. Plant Protection and Quarantine. 3, 48 (In Russian with English summary).

Nascimento M., Garcia M., da Silva K., Pinto-da-Silva L., Atella G., Motta M.C.M. and Sa-raiva E.M. 2010. Interaction of the monoxenic trypanosomatid Blastocrithidia culicis with the Aedes aegypti salivary gland. Acta Trop. 113, 269-278.

Nguyen L.T., Schmidt H.A., von Haeseler A. and Minh B.Q. 2015. IQ-TREE: a fast and effective stochastic algorithm for estimating maximum-likelihood phylogenies. Mol. Biol. Evol. 32, 268-274.
Ohbayashi T., Takeshita K., Kitagawa W., Nikoh N., Koga R., Meng X.Y., Tago K., Hori T., Hayatsu M., Asano K., Kamagata Y., Lee B., Fukatsu T. and Kikuchi Y. 2015. Insect's intestinal organ for symbiont sorting. Proc. Natl Acad. Sci. U S A. 112 (37), E5179-88.

Otero-Bravo A. and Sabree Z. 2018. Comparing the utility of host and primary endosymbiont loci for predicting global invasive genetic structuring and migration patterns. Biol. Control. 116, 10-16.

Pacheco R.S., Marzochi M.C., Pires M.Q., Brito C.M., Madeira M. and Barbosa-Santos E.G. 1998. Parasite genotypically related to a monoxenous trypanosomatid of dog's flea causing opportunistic infection in an HIV positive patient. Mem. Inst. Oswaldo Cruz. 93 (4), 531-537.

Parthasarathy M.V., Van Slobbe W.G. and Soudant C. 1976. Trypanosomatid flagellate in the Phloem of diseased coconut palms. Science. 192, 1346-1348.

Podlipaev S.A. and Frolov A.O. 1987. Description and laboratory cultivation of Blastocrithidia miridarum sp. n. (Mastigophora, Trypanosomatidae). Parazitologiya. 21, 545-552 (in Russian with English summary).

Ravoet J., Schwarz R.S., Descamps T., Yanez O., Tozkar C.O., Martin-Hernandez R., et al. 2015. Differential diagnosis of the honey bee trypanosomatids Crithidia mellificae and Lotmaria passim. J. Invertebr. Pathol. 130, 21-27.

Ronquist F., Teslenko M., van der Mark P., Ayres D.L., Darling A., Hohna S., et al. 2012. MrBayes 3.2: efficient Bayesian phylogenetic inference and model choice across a large model space. Syst. Biol. 61 (3), 539-542.

Schaub G.A. and Schnitker A. 1988. Influence of Blastocrithidia triatomae (Trypanosomatidae) on the reduviid bug Triatoma infestans: alterations in the Malpighian tubules. Parasitol. Res. 75 (2), 88-97.

Schaub G.A., Böker C.A., Jensen C. and Reduth D. 1989. Cannibalism and coprophagy are modes of transmission of Blastocrithidia triatomae (Trypanosomatidae) between triatomines. J. Protozool. 36 (2), 171-175.

Schaub G.A. and Jensen C. 1990. Developmental time and mortality of the reduviid bug Triatoma infestans with differential exposure to coprophagic infections with Blastocrithidia triatomae (Trypanosomatidae). J. Invertebr. Pathol. 55 (1), 17-27.

Schwarz R.S., Bauchan G.R., Murphy C.A., Ravoet J., de Graaf D.C. and Evans J.D. 2015. Cha- 
racterization of two species of Trypanosomatidae from the honey bee Apis mellifera: Crithidia mellificae Langridge and McGhee, and Lotmaria passim n. gen., n. sp. J. Eukar. Microbiol. 62, 567-583.

Sunter J. and Gull K. 2016. The flagellum attachment zone: "the cellular ruler" of trypanosome morphology. Trends Parasitol. 32 (4), 309-324.

Taylor C., Coffey P., DeLay B. and Dively G. 2014. The importance of gut symbionts in the development of the brown marmorated stink bug, Halyomorpha halys (Stål). PLoS One. 9, e90312.

Tieszen K.L., Molyneux D.H. and AbdelHafez S.K. 1986. Host-parasite relationships of Blastocrithidia familiaris in Lygaeus pandurus Scop. (Hemiptera: Lygaeidae). Parasitology. 92, 1-12.

Tobie E.J. Fate of some culture flagellates in the hemocoel of Rhodnius prolixus. 1965. J. Parasitol. 54 (5), 1040-1046.

Týč J., Votýpka J., Klepetková H., SulákováH., Jirků M. and Lukeš J. 2013. Growing diversity of trypanosomatid parasites of flies (Diptera: Brachycera): frequent cosmopolitism and moderate host specificity. Mol. Phylogenet. Evol. 69, 255-264.

Vetek G., Papp V., Haltrich A. and Redei D. 2014. First record of the brown marmorated stink bug, Halyomorpha halys (Hemiptera: Heteroptera: Pentatomidae), in Hungary, with description of the genitalia of both sexes. Zootaxa. 3780, 194-200.

Vickerman K. 1969. On the surface coat and flagellar adhesion in trypanosomes. J. Cell. Sci. 5, 163-193.

Votýpka J., Maslov D.A., Yurchenko V., Jirků M., Kment P., Lun Z.R. and Lukeš J. 2010. Probing into the diversity of trypanosomatid flagellates parasitizing insect host in South-West China reveals both endemism and global dispersal. Mol. Phylogenet. Evol. 54, 243-253.

Yourth C.P. and Schmid-Hempel P. 2006. Serial passage of the parasite Crithidia bombi within a colony of its host, Bombus terrestris, reduces success in unrelated hosts. Proc. R. Soc. Lond. [Biol ]. 273 (1587), 655-659.

Yurchenko V., Lukeš J., Jirků M., Zeledon R. and Maslov D. A. 2006. Leptomonas costaricensis sp. n. (Kinetoplastea: Trypanosomatidae), a member of the novel phylogenetic group of insect trypanosomatids closely related to the genus Leishmania. Parasitology. 133, 537-546.

Address for correspondence: Marina Malysheva. Zoological Institute, Russian Academy of Sciences, Universitetskaya Emb. 1, 199034 St. Petersburg, Russia; e-mail: malmarnik@yandex.ru 